\title{
Use of Multimedia as a New Educational Technology Tool: An Overview and Its Future
}

\author{
Rajesh Kumar $^{1}$, Ashish Agarwal ${ }^{2}$ \\ ${ }^{1} \mathrm{Ph}$. D Scholar, School of Management, Shri Venkateshwara University, Gajraula, Amroha (UP), India \\ ${ }^{2}$ Professor, Indira Gandhi Open University (IGNOU), Delhi India
}

\begin{abstract}
Multimedia has become a focus of research in educational delivery, learning and its assessment. This paper looks at how multimedia is used in education as an educational tool, discussing how the materials are used in teaching and how human learners are treated with the underlying curriculum and learning theories and assumptions contained in them about the nature of knowledge, instruction and learning. The paper also discusses the advantages, requirements and the limiting factors to be considered for creation of multimedia applications in education.
\end{abstract}

Keywords: Multimedia, Pedagogy, Technology, Hypermedia

\section{Introduction}

Educators continually search for more effective ways to engage their students during learning as well as to increase student learning outcomes. In order to achieve educational effectiveness, it is important for the educators to adopt an effective teaching method with the assistance of advanced technology that suites the individual's learning style. Various technologies have been touted as being able to provide ultimate delivery mechanism to achieve these laudable goals. However the technologies purporting to provide solutions are changing at an exponential pace, the true effect of these technologies on learning outcomes remains unclear.

Multimedia computer based training and learning including hypermedia technology has been an area of research for the educational experts. There are different courseware designed for teaching and learning and they have been proven effective in accelerating the process of learning. The conventional way of teaching and learning is empowered with the advent of multimedia technology. Multimedia technology also enriches the content of computer based education by providing media rich study materials for students. Furthermore, it changes the way that the end users are interacting with computer systems. Experiences of the researchers in evaluating the quality of learning from hypermedia documents has been highly positive and it has been established that some of the positive attitude is due to the novelty of the medium (Brown, 1995).

The paper begins with a review of what educators and researchers consider multimedia and its importance in learning process. Then the paper looks at how multimedia is used in education including survey of the state of art in use of multimedia as an educational tool, discussing how the materials are used in teaching and how human learners are treated with the underlying curriculum and learning theories and assumptions contained in them about the nature of knowledge, instruction and learning. The paper also discusses the advantages, requirements and the limiting factors to be considered for creation of multimedia applications in education.

\section{Literature Review}

Humans receive data through multiple channels, i.e. media including audio and visual channels (Paivio, 1969) as well as touch, taste and smell. Multimedia is most commonly defined as the use of at least two of these elements: sound (audio), text, still graphics, and motion graphics (visual) (Tannenbaum, 1998). To date, the majority of the educational research projects do not include the other media of touch, taste and smell. The importance of multiple channels for delivery of educational content can be found in the theory of multi-channel communication which confirms that when information is presented by more than one channel, there will be addition reinforcement, resulting in greater retention and improved learning (Ellis, 2004; Bagui, 1998; Daniels, 1999).

Furthermore, although not stipulated by most researchers assessing the effectiveness of instructional multimedia, Tannenbaum (1998) posits that multimedia must include an interactive component. This interactive component must allow the learner to interact with the material in such a way as to control the outcome of the presentation, thereby necessitating that it be under the control of a computer (Tannenbaum, 1998). In fact, Drave (2000) suggests that the quality of interactivity is more important than content for the success in learning. (Evans \& Gibbons, 2007, 1148). The importance of the interactive component is supported by the constructivist learning theory that says that an enhanced degree of control results in deeper learning outcomes (Smock, 1981; Zimmerman, 1981 by Ellis 2004). Thus, although some educators may define the use of PowerPoint as a form of multimedia (Butler and Mautz, 1996), few utilize its interactive components, and therefore it fails to meet Tannebaum's (1998) definition of a "strong" form of multimedia. Instead it would appear to constitute a "weaker" form of multimedia based on its use of text, sound, and animation. However, there has been extensive research into the use of PowerPoint as a multimedia learning tool, and therefore in keeping with this paper's purpose, some of that research is included. 
International Journal of Science and Research (IJSR)

ISSN (Online): 2319-7064

Index Copernicus Value (2013): 6.14 | Impact Factor (2014): 5.611

\section{Multimedia and Education}

\subsection{What Is Multimedia?}

Multimedia is a melody sung in harmony with multi-channel and multi-modal bits of knowledge and creation. Sometimes it is as small as a rotating globe used as logo in an amateur's website or is as huge as Xbox 360 games or Dream Works' Shrek series. Its ultimate role is to inform, educate and/or entertain all. Multimedia is all-pervading, thrilling and involving method of information, education \& entertainment with multiple facets and long lasting approbation.

\subsection{Educational Technology}

Educational technology is the study and ethical practice of facilitating learning and improving performance by creating, using and managing appropriate technological processes and resources. It is most simply and contentedly defined as an assortment of tools that might prove helpful in student centered learning, problem based learning or case-based learning. It advocates the teacher becoming "Guide on the Side" rather than "Sage on the Stage" (A. King, 1993). Educational Technology also called "Learning Technology", mainly comprise of the use of technology in the process of teaching and learning. Here the term "Technology" does not only include the use of latest tools and techniques like laptops, interactive whiteboards, smart phones, internet, WiFi, and YouTube etc., although they are massively preferred by today's learners for their learning potential, but also encompasses efficient and enhanced learning management systems, schema of information dissemination, effective teaching and management of student masses, feedback mechanisms and performance evaluation methodologies etc.

\subsection{Multimedia Learning Environment}

Multimedia provides a technology based constructivist learning environment (M. Neo and T.K. Neo, 2009) where students are able to solve a problem by means of selfexplorations, collaboration and active participation. Simulations, models and media rich study materials like still and animated graphics, video and audio integrated in a structured manner facilitate the learning of new knowledge much more effectively. The interactive nature of multimedia provides the room to enhance traditional "chalk-and-talk" method of teaching (Indira dhull \& Suman beniwal, 2013) with more flexibility to learners to adapt to individual learning strategy. It enables both the educators and learners to work together in an informal setting. The role of educators and learners are extended. Furthermore, it encourages and enhances peer learning as well as individual creativity and innovation.

\section{Multimedia and its Pedagogical Strengths}

Multimedia facilitates mastering basic skills of a student by means of drill and practice. It helps in problem solving by means of learning by doing, understanding abstract concepts, provide enhanced access for teachers and students in remote locations, facilitate individualized and cooperative learning, helps in management and administration of classroom activities and learning content, and simulate real life problem handling environments. Multimedia Technology is used and experimented by various educational institutions of all levels all over the world in their own designed modes.

\section{Multimedia in Educational Context}

One of the factors determining the educational effectiveness is how educators communicate their conceptual knowledge to the learners. Traditionally, text is used as the basic medium for delivering knowledge and information to the intended learners. This might be adequate in some context, but might not be true in another.

The process of knowledge acquisition can be more effective if the learners can experience an event through computer simulation incorporating multimedia in a seamless way. Multimedia technology empowers the teaching and learning process. It allows educators to include multiple media into the teaching materials and makes the study more interesting or even more motivated. It improves the quality of education as well as the interaction between teachers and the students. Furthermore, it encourages and enhances peer learning as well as individual creativity and innovation.

In the conventional education framework, as shown in Figure 1, consists of two main entities: Educator and Learner. The communication between these two entities is basically a one way process.

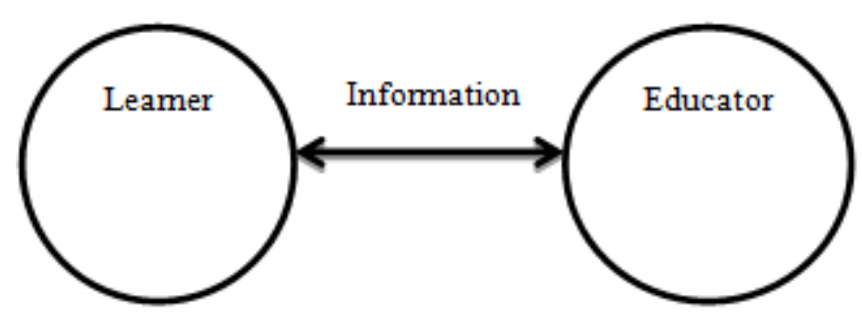

Figure 1: The conventional education framework

Educator normally plays the role as information provider who delivers conceptual knowledge to the learners. Learner is the receiver of this knowledge, but how and how much they could really absorb is merely answered. There is no mechanism to effectively aid the learner to process and comprehend these abundant information and knowledge. The effectiveness of the education in this setting is questionable. Multimedia has the capability to empower the constructivist approach for learning through collaborations, self-explorations, simulations, models and creating media rich study materials. Pictures, video and sounds are incorporated in a structured manner facilitating the learning of new knowledge much more effectively.

The interactive nature of multimedia can also provide the learners more flexibility to adapt to their own learning strategies. It enables both the educators and learners to work together in an informal setting. The role of educators and learners are extended. Figure 2 demonstrates our view of multimedia courseware as a communication channel between teachers and students which re-engages and accelerates the education process. 


\section{International Journal of Science and Research (IJSR) \\ ISSN (Online): 2319-7064}

Index Copernicus Value (2013): 6.14 | Impact Factor (2014): 5.611

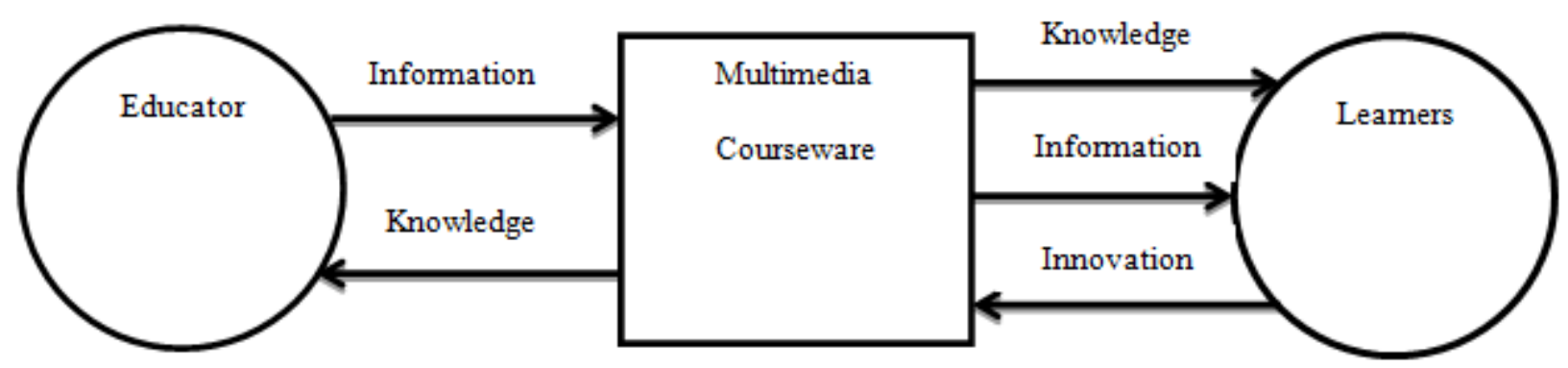

Figure 2: Multimedia re-engages and accelerates the education process

The educators can learn the instructional needs of intending learners and thus the new understanding of a subject might also be discovered. The MCAT/MCAL applications can be developed and delivered on the CD-ROM or online through the Internet. Learners can have access to them regardless of the time and space.

\section{Requirements for Multimedia Educational Tools}

The creation of MCAT/MCALs has four main stages. These stages are initial design, developing, delivery and maintenance, as shown in Figure 3. All these four stages form an on-going cycle of process.

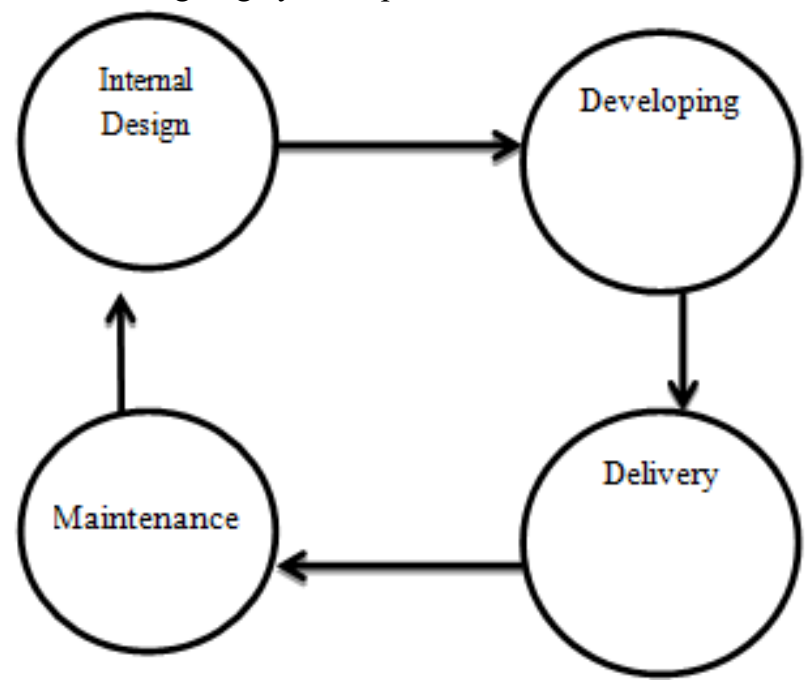

Figure 3: The process of creating MCAT/MCAL tool

The initial design stage involves the gathering of ideas, requirement, identification all necessary elements of course materials, and feasibility studies, which states the suitability of the product to the existing teaching and learning methods. In the developing stage, creators of the product proceed with all necessary resources. At the delivery stage, we are concern about how the MCAT/MCALs material can be delivered more cost effectively (such approach might be through Internet or CD-ROM or a combination of both).

The fourth stage is an on-going process of maintenance. In this process, the users and developers will be continuously updating the content and improving the functionality of the MCAT/MCALs system. The users play an important role in all the four stages of CAT/MCALs creation. Four main characteristics to be incorporated in the multimedia educational materials are:
Interactivity: MCAT/MCAL tools shall not just "deliver" information to the learners, but also enable interactive learning. Educators and learners should be capable of getting immediate responses of their actions during the process of knowledge seeking and exploration.

Collaboration: Multimedia education tool shall provide environment for collaboration among the intended users, both learners and educators. Simultaneous access to a multimedia resource (i.e. video clip, audio segment, picture, etc) by multiple users is essential for collaborated learning and teaching.

Self-Exploration: In general, different people have different capacities of sense making. This is due to our different sense making training. Thus when people process the same piece of information, they will apply their unique way of sense making methods. One of the recommended learning methods is self-exploration. Through self-exploration of knowledge, new understandings of a subject can be constructed more effectively. This has specific benefits to students who find the conventional way of education insufficient for their learning. The introduction of multimedia technology as an instructional tool allows the educators to "deliver" knowledge more dynamically through media rich course materials, and hence encourages the students to learn more effectively by matching their diverse learning patterns and instructional needs.

Encourage Innovation: The MCAT/MCALs should allow learners to express their understanding to a specific subject of knowledge innovatively and dynamically. This also encourages the learners to participate in the learning process positively while they are gaining more confidence in manipulating course materials and are able to create something that their peers might not be able to do, thus allowing other learners and educators to explore the knowledge of a domain in many dimensions.

\section{The Applications of Multimedia in Education}

Multimedia technology plays an important role in the education and training because of its ability to provide a virtual environment for learners to effectively acquire knowledge. With sound and visual effects, multimedia enhances the computer simulation of the real life events. It has the potential to transform the classroom from a physical world to an unlimited imaginary virtual environment. 


\section{International Journal of Science and Research (IJSR) \\ ISSN (Online): 2319-7064}

Index Copernicus Value (2013): 6.14 | Impact Factor (2014): 5.611

Multimedia simulations can instantly put the learners in an environment where they can discover, explore more knowledge actively. It has also made many kind of training easier, such as firefighting, driving and flight simulations. Visual and audio can powerfully affect the learners processing of information. This has also given a chance and new life to the physically handicapped learner in accessing electronic information. For example, a multimedia database server may store electronic information in different versions for the same information (both visual and audio) suitable for different kind of information needs.

There have been tremendous amount of MCAT/MCAL applications targeting diversity of domains such as schools, family, professional training and employees job training. Some of these applications from our survey and a brief overview of their features are discussed in the subsequent sections. Generally speaking, these MCAT/MCAL applications can be categorized into the three major domains as shown in Figure 5.

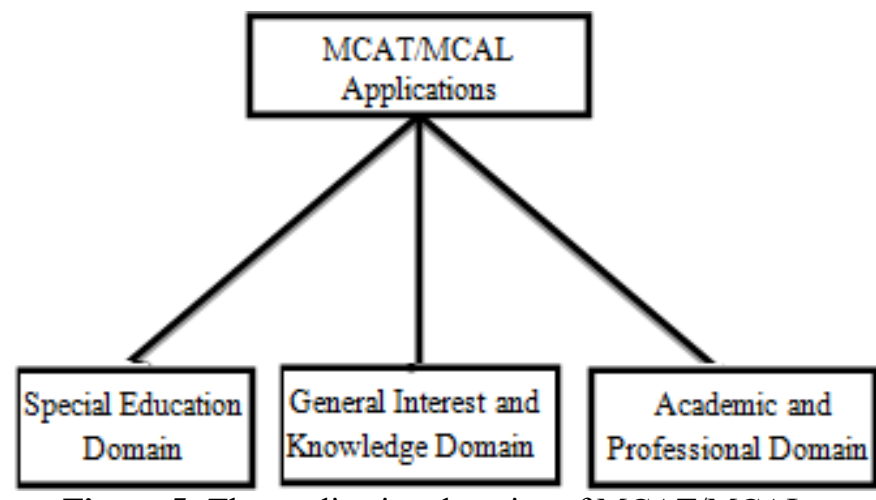

Figure 5: The application domains of MCAT/MCAL

\section{Special Education Domain}

Computerized multimedia based educational tools (MCAT/MCAL) are increasingly used in the special education domains. Such systems allow people with visual disabilities, who cannot read textual or graphical information, to access audio information through the audio aids while people with hearing disability can learn more effectively through visual presentation of multimedia information. Multimedia also helps learning disabled or attention deficit learners to participate better in the learning process. Other applications of $\mathrm{MCAT} / \mathrm{MCAL}$ are for facilitating learning, enhancing social interaction and to help building self-esteem among those students with behavioral and emotional difficulties. Learners are able to express themselves with the aids of these tools. Examples for these kind of multimedia applications are, a multimedia CAT/CAL system equipped with MIDI synthesizers, music software, etc. (Holzberg and Carol, 1994) at Waterford Country School in Quaker Hill, Connecticut, a school for youngsters ages 10-18 with intellectual disabilities. The system is implemented to complement the school's curriculum.

The system is well equipped with multimedia computers, scanners, MIDI synthesizers, video, and music software. With the aid of the system, students' written communication is significantly improved while they can incorporate pictures into their work to help express them. Students' self-esteem and self-confidence are gradually increased while their communication skills improving. Thus, students are more encouraged to work cooperatively with others. For those students with musical talent, computer based music programs enable them to create music and express themselves musically.

The Conroy Education Center (Holzberg and Carol, 1994) is a special education school in Pittsburgh, PA, where multimedia technologies are adopted to complement the education of adolescents with developmental delays to protect themselves against victimization. The school's laboratory is divided into three areas to focus on academic skill building, telecommunications, and anti-victimization training. A potential victimization scenario (i.e. teenagers are involved in the preparation of a party) created by a multimedia simulation software package on five interactive video stations is used to assist anti-victimization training.

\section{General Interest and Knowledge Domain}

There is a wide range of different applications for these specific domains, such as language learning, history, scientific knowledge, stories, etc. The World Book Multimedia Encyclopedia tm by World Book Educational Products and the World Book Information Finder are designed for grade $3+$ students to learn real life world events by storytelling through interactive pictures, video and sound. The Insight tm provides an interactive multimedia environment for the learners to explore the career options and personalized printouts at the end of a session.

The Triple Play Plus! Language Learning tm delivered on CD-ROM is a multimedia language learning package featuring with Automatic Speech Recognition to evaluate the learner's pronunciation. The interactive multimedia games and comic strips instruct the learners to read, speak and understand words and phrases of a foreign language, including Spanish, French, German and English. Ultra Key tm provides complete keyboarding instruction using animation and voice. Ultra Writer tm assists learners to develop writing skills through hands on writing.

The Electronic Home Library includes over 250 different kinds of historical, philosophical, classical and political works Library. ELLIS tm by CALI Company is another interactive English Language Learning and Instruction System.

The ELLIS curriculum provides an user friendly environment with interactive graphics, full motion video, digitized sound and voice recording and animation for ESL/EFL learners. Educational application packages for kids' reading and writing are such as LIVING BOOKS tm is an animated storybook series on CD-ROM that helps kids to read with sounds and animated videos in English, Spanish, and Japanese. The STORY BOOK WEAVER DELUXE tm is a CD-ROM multimedia package that helps kids to illustrate and write stories in English or Spanish with sound effects, music and graphics (Source: T.H.E. Journal, May 1995).

\section{Volume 5 Issue 1, January 2016}




\section{International Journal of Science and Research (IJSR) \\ ISSN (Online): 2319-7064}

Index Copernicus Value (2013): 6.14 | Impact Factor (2014): 5.611

In the area of scientific knowledge learning, 'the Science Sleuths CD-ROM For Kids' (Anis and Nick, 1994) allows small children to learn science knowledge through solving real life science mysteries by applying research skills and scientific principles used by actual scientists and engineers. The question and answer schema encourages the learners to articulate scientific theories.

This package consists of a unique set of stimulated, interactive experiments and tests, along with a library of multimedia resources. Learners can choose from a list of science mysteries to solve. The "Sleuth Headquarters" is a virtual reality science laboratory where the learners can simulate experiments with multimedia resources and more than a dozen interactive scientific tools, such as a Bunsen burner, microscope, and Geiger counter. Live video clips and interviews of witnesses and experts in the scientific fields are also utilized to complement the learning process. An interactive "notebook" allows the learners to record their findings and hypotheses and a final report or "case" is produced and printed out. The Master Sleuth determines if they have solved the mystery and tests their knowledge of key scientific concepts.

\section{The Academic and Professional Domain}

It includes subject specific multimedia courseware and computer simulation for laboratory experiments, such as simulations for pilot training, firefighting and engineering design. There are also a number of systems created by universities, such as the School of Engineering and Technology at Deakin University [HREF 1] implemented an Internet based Hypertext/ Hypermedia MCAT/MCAL for students. Students are allowed to navigate through the course material in an interactive multimedia environment through the "interactive image maps" and hyperlink features of the system. The students' study materials incorporate multiple media types, such as image, video and audio.

The system empowers the students' learning process by allowing them to communicate with the teachers and peers electronically through HTML forms. The multimedia courseware developed by Biodiversity Consortium [HREF 2] for the first year undergraduates in biology science consists of two major components: the teaching materials (UNIT) and the courseware delivery engine (the Scholar's Desktop) which is an interactive multimedia interface effectively assisting the learners in accessing the study materials. Video, sound and pictures are used to enrich the content of the system which makes the learning more interesting.

Another application the CAL/Multimedia Projects in Electronic Engineering is an ongoing multimedia CAT/CAL project in University of Wollongong [HREF 3]. The system consists of three main modules: Computer Aided Tutorial (CAT), Computer Aided Laboratory Experiment (MCALE) and Computer Aided Self Learning (CASL). Learners and educators can exchange information and give feedback through the interactive multimedia environment.

Multimedia simulation based Power System Education is also a MCAT/MCAL project in University of Wollongong
[HREF 4] which is an computer based teaching/learning methods to assist learners to fit into the highly advance power systems industry through simulation of problem solving and experiments. Learners and teachers can exchange ideas and discuss problems in an interactive multimedia environment.

The Office Simulator [HREF 5], a multimedia office training system provides simulated business training program to the users. The computer simulation with sound and pictures bring the learners to an interactive virtual office environment where they can explore the objects by clicking on it. Instructions and messages am delivered to the learners in multiple media forms.

Coiro et al (1993) described an experimental multimedia $\mathrm{CAT} / \mathrm{CAL}$ for distance learning, implementing on digital telecommunications facilities. This system is designed for distance learning purposes and supports various kinds of sessions. It allows the users to exchange video, voice and data simultaneously. There are two types of channel connections setup to support the distribution of multimedia data, the isochronous or asynchronous channels. The formal one enables the distribution of real time audio and video with the required quality, whereas the later one or a combination of both support still images (with various resolution), animation, and graphics. The implementation has two specially equipped classrooms currently setup in two separate towns. These classrooms are facilitated with cameras, video projectors, video codec's, multiplexers and a specialized still image management system. For primary school education, Smith and Maureen (1995) described an Internet based multimedia CAT/CAL system for the sixth grade geography students at the Minnetonka Middle School. The students study the geography, culture, climate, ecology, and biology of various regions through multimedia electronic expeditions on the Internet.

The multimedia curriculum in history, art, science, ecology, math, biology, and anthropology enrich the students' exploration and study. The system also provides other facilities, such as electronic mail, forum discussions, FTP for downloaded photos, graphics, and real time question and answer sessions between students and domain experts from different areas of scientific research.

The Students and Teachers Integrated Learning Environment (The STILE) is a resource base approach using hypermedia to provide greater opportunities for independent and flexible modes of learning and mechanism for both educators and learners to discover and access relevant resources as they require them, together with facilities that enable users readily to use and re-use existing materials of their own in a way that seems natural to them (Ruggles, 1995)[17]. Thus it is considered as a set of tools and services and a continually developing resource base rather than a closed and finished product.

\section{Problems and Issues of Multimedia CAT/CAL}

The use of multimedia technology in the educational environment has not yet reached its mature stage. We have identified some of the factors that require attention towards 


\section{International Journal of Science and Research (IJSR) \\ ISSN (Online): 2319-7064}

Index Copernicus Value (2013): 6.14 | Impact Factor (2014): 5.611

successful realization of MCAT/MCAL within an organization. Thus, it explains the current state of multimedia technology in educational domain. The three major factors are Organizational, Technological and Human as shown in Figure 6.

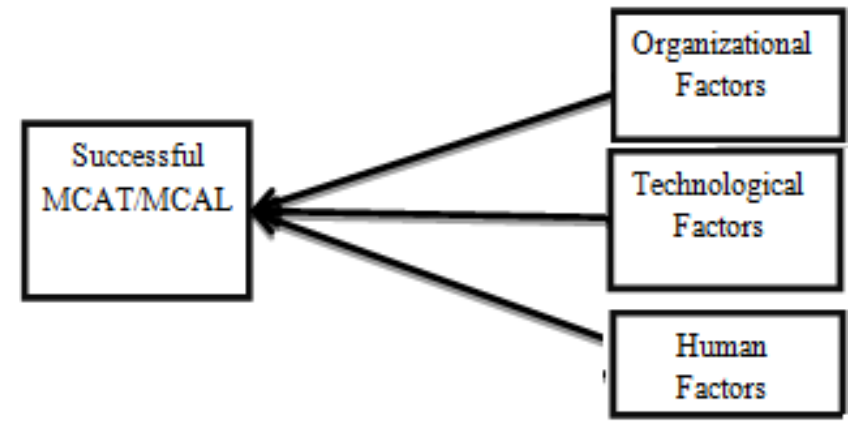

Figure 6: Factors contributed to successful MCAT/MCAL

\section{Organizational Factors}

Without a well formulated plan for adopting this new technology, conflicts are likely to occur within an organization, and thus become a limitation and hinder the realization of multimedia in education. Rapid changes are brought to the organizations because of the transition from the traditional text based teaching modes to a new style of computerized multimedia instruction. Resistance to changes is a natural phenomenon of human being. Resistance will occur while the benefit of the change is not justifiable to the cost. The cost of adopting multimedia technology as an educational tool is still expensive in the present day. An extra overhead will be added to the educational expenses in the process of acquiring hardware and software equipment's. The

creation and delivery of multimedia instructional tools as well as training and maintenance are time consuming and costly process. Development of multimedia study materials requires intensive input of time and effort from the educators. Lack of time and qualified personnel to develop quality MCAT/MCAL causes limitations to provide interesting and innovative materials to the students. Hiring professional multimedia developers requires a substantial cost.

The cost of developing multimedia courseware could be too expensive as it may require people with different skills in creating meaningful multimedia presentation and instructional packages. For example, for creating an one hour video for courseware material, it might need some "actors" and "directors". The educational organization might not be willing to invest for the multimedia technology since it still remained unjustifiable that multimedia will reduce the cost of education.

There is also a lack of sufficient incentive and rewards towards the contribution to the multimedia materials development. These activities do not count sufficient credit toward tenure and promotion. As such the Center for Innovative Technology at South Carolina State University discourages assistant or associate professors from becoming too involved in developing multimedia materials. They suggest that only full professors can afford to spend time in this manner (Solomon and Martin, 1994).

\section{Technological Factors}

A lack of standardized tools, system development methodologies and platform standards have all contributed to slow integration for multimedia $\mathrm{CAT} / \mathrm{CAL}$ materials development. The multimedia enable software and hardware are still expensive (a low end multimedia enable personal computer with desirable performance is priced around $\$ 1,500+)$. Most of the multimedia authoring tools do not allow the end products to be interchanged with other tools. This posts a disadvantage on the sharing and exchanging study materials among courseware developers.

The lack of standardized multimedia system development methods and data formats result in the incompatibility among multimedia educational systems. There are at least twenty different types of data format just for still image (such as GIF, JPEG, JIFF, BMP, XBM etc.). For video information, there are not less than ten types of formats, such as MPEG, FLI, AVI, MOV, etc. For audio data, the numbers of file formats are as many as still image, such as WAV, AU, AIFF, etc. Different vendors have their own commercial interests and supporting various types of methodologies.

As a matter of fact, most of the multimedia application systems do not directly communicate with one the other unless they are developed under the same company. Therefore, there is a need to have a convergence for the multimedia application development methods as well as the various types of media formats and standards. Although multimedia technology has made many ways of teaching and training possible and with the aids of multimedia instructional tools the learners are able to learn faster through audio and visual simulations, but there are still things that currently available multimedia technology cannot do. The conventional face to face in person teaching method still has advantages over the high tech ones. The availability of MCAT/MCAL comes down to whether the users have access to the multimedia equipped computers and other associated resources such as connection to the Internet.

\section{Human Factors}

There is a lack of experience of educators in manipulating multimedia computer based instructional tools. Most educators do not have sufficient computing knowledge, training and skills in graphic design, computer programming and authoring multimedia courseware.

Educators will need to be retrained in order to have better result of adapting to the new technology. Furthermore, problems might occur as a result of the difference in abilities of individuals to learn a new skill. Substantial time efforts might be needed for the educators to learn and manipulate these new technologies. It might not be an easy task for aged teachers. Empirical study has shown that an older employee within an organization has more difficulties to adapt to the new technologies than the younger ones (Staufer, 1992). 


\section{International Journal of Science and Research (IJSR) \\ ISSN (Online): 2319-7064}

Index Copernicus Value (2013): 6.14 | Impact Factor (2014): 5.611

There is also a lack of sufficient time for the educators within a teaching institution to participate in the creation of multimedia courseware development where the workload for their teaching is already high enough. Organizations therefore need to formulate a strategy to assist these groups of educators to cooperate with the new style of teaching. Another issue is to justify about how people can learn best. It is difficult to develop a corporate interactive multimedia environment for learning which will fulfill everybody's educational needs.

\section{Conclusion}

There is no doubt about the advantages that multimedia technology can be used as a powerful tool to assist educators to achieve educational effectiveness. It has been illustrated in this paper that adopting multimedia technology in education has made it possible to achieve effective teaching and training in multiple domains which was not possible in the traditional text based environment. However, the research experience made it evident that the provision of tools does not in itself lead to a successful outcome (Ruggles, 1995). Incorporating multimedia technology in a dynamic system with good quality materials for students to access, it is now possible to develop effective new teaching and learning strategies. The optimal use of multimedia technology in education and its full potential will only be realized if it is to be adopted not only as a vehicle for knowledge "delivery", but most importantly as an instructional tool. Though creating a good multimedia educational tool has high cost involving the time and effort of the author, the reason for developing these applications is to improve the quality of learning. The multimedia technology as a whole has not yet reached its mature stage. There are still many inhabited problems needed to be solved before educators can make even better use of it and thus beneficial to the learners. The cost effectiveness of multimedia cannot be achieved in the short term. As such portability, maintenance and quality assurance issues needs to be considered seriously even with extra investments to make the project long term economic (Brown, 1995). Organizations' should formulate a long term plan for the adoption of multimedia technology in their educational context so that its full potential can be realized.

\section{References}

[1] Anis and Nick (1994). Science Sleuths CD-ROM for kids. Newsbytes Nov 4, pNEW 11040002

[2] Association for Educational Communications and Technology (AECT) Definition and Terminology Committee June 1, 2004, the Definition of Educational Technology

[3] Bagui, S. 1998. Reasons for increased learning using multimedia. Journal of Educational Multimedia and Hypermedia, Vol 7, No. 1. 3-18.,

[4] Brown, P.J. (1995), creating educational hyper documents: can be economic? Innovations in education and training international, 32 (3), August, 201-208

[5] Coiro, S. et al (1993). Design and experimental monitoring of an ISDN based multimedia distance learning service. Proceedings of the 3rd Tele-teaching Conference, TeleTeaching 93 IFIP Transactions A: Computer Science and Technology, n A-29, p157-166, Norway.
[6] Daniels, L. 1999. Introducing technology I the classroom; PowerPoint as a first step. Journal of Computing in Higher Education, 10, 42-56.

[7] Drave W. 2000. Teaching online. River Falls, Wisconsin: LERN books Ellis, Timothy. 2004. Animating to build higher cognitive understanding: A model for studying multimedia effectiveness in education. Journal of Engineering Education. January 2004.

[8] Ellis, Timothy. 2004. Animating to build higher cognitive understanding: A model for studying multimedia effectiveness in education. Journal of Engineering Education. January 2004

[9] Evan, Chris and Nicola J. Gibbons, 2007. The interactive effect in multimedia learning, Computers \& Education. 49 $1147-1160$

[10] Holzberg and carol, 1994 Magazine Article, Technology \& Learning, Technology in special education

[11] King, A. (1993). "From Sage on the Stage to Guide on the Side." College Teaching Vol. 41, No. 1 (Winter), pp. 3035.

[12] M. Neo and T. K. Neo, (2009). Engaging students in multimedia-mediated Constructivist learning - Students" perceptions. Educational Technology \& Society. vol. 12, no. 2, pp. 254-266.

[13] Paivio, Allan, Mental imagery in associative learning and memory, American Psychological Association, Psychological Review, Vol 76(3), May 1969, 241-263.

[14] Prof. Indira Dhull and Ms. Suman Beniwal, "Chalk on talk method", Role of Multimedia in Teaching Learning Process, Advanced International Research Journal of Teacher Education, Vol. 1, No. 2, Sep. 2013, ISSN: 23204559, E-ISSN: 2321-7995

[15] Ruggles, C., Underwood, J. and Walker, D. (1995). STILE: A hypermedia approach to the provision of a flexible, interdisciplinary resource base for teaching and learning. Innovations in Education and Training International, 32(3), August, p 209-219.

[16] Smith and Maureen (1995). The new "Trekkie:" Students travel from the Arctic to Brazil over wire (online expeditions). Electronic Learning, Feb, 14(5), p26(3), Scholastic Inc.

[17] Smock, C. D. 1981. Constructivism and educational practices In I.E. Sigel, D.M. Brodzinski \& R.M. Golinkoff (Eds.), New Directions in Paigetian Theory and Practice. . Hillsdale, NJ: NJ: Erlbaum. 51-68. Stoloff, M. 1995. Teaching physiological psychology in a multimedia classroom. Teaching Psychology. 22. 138-141

[18] Solomon and Martin (1994). What's wrong with multimedia in higher education? $\mathrm{T} \mathrm{H}$ E Journal (Technological Horizons In Education), 21(7), p81(3).

[19] Staufer, M. (1992). Technological change and older employees: Implications for introduction and training, Behavior and Information Technology, 11(1), 46-52

[20] Tannenbaum, Robert S. 1998. Theoretical foundations of multimedia. New York: Computer Science Press

[21] T H E Journal - Technological Horizons In Education (May 1995), 22(10), pS1 (64)

[22] Zimmerman, B.J. 1981. Social learning theory and cognitive constructivism. In I.E. Sigel, D.M. Brodzinski \& R.M. Golinkoff (Eds.), New Directions in Paigetian Theory and Practice. . Hillsdale, NJ: NJ: Erlbaum. 39-49 